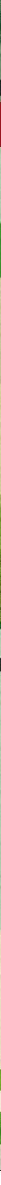

\title{
CARBON NEUTRAL AVIATION
}

\author{
- Rob Terwel ${ }^{1}$, John Kerkhoven ${ }^{1}$ and Frans W. Saris ${ }^{2}$ - DOI: https://doi.org/10.1051/epn/2019503 \\ - ${ }^{1}$ Kalavasta b.v. $-{ }^{2}$ Foundation Sanegeest
}

\section{The aviation industry can become carbon neutral by $\mathrm{CO}_{2}$ recycling into synthetic kerosene using renewable energy. As an example we take $\mathrm{CO}_{2}$ emissions from Tata Steel in the Netherlands as well as Schiphol Airport's kerosene consumption.}

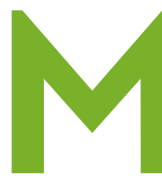

odern airplanes emit $\mathrm{CO}_{2}$ as they burn kerosene in their jet engines. Flying is therefore one of the human activities that contributes

to global warming. Direct emissions from aviation are more than $2 \%$ of worldwide emissions and are set to grow by approximately 2.5 - 3.5\% (including efficiency gains) every year for the next 30 years in Europe (1). Compared to 2017, kerosene usage would easily double towards 2050 and could even rise to up to 5 times current levels if efficiency targets would not be realised. In 2009 the International Air Transport Association (IATA) set a goal to halve $\mathrm{CO}_{2}$ emissions by 2050 with respect to 2005 (2). Without additional measures projections are a factor of 6 - 10 times worse than what IATA aims for. The International Civil Aviation Organization (ICAO) launched the CORSIA program which sets out to offset any emissions above 2020 levels through emission trading (3). Participation becomes mandatory for all States committed in 2027. Given that as a society we do not seem to want to give up flying, we need to find a solution that meets - and ultimately goes beyond - IATA's longterm target and emission offsetting.

\section{Solutions from other sectors \\ do not work for aviation}

While in other sectors technologies are available that would allow the sector to become carbon neutral, this is not likely to be the case in the aviation sector soon.

For instance, one can switch from a car with an internal combustion engine on petrol to a battery electric vehicle "fuelled" by electricity from a wind- or solar source. As a result, the activity of driving (excluding the manufacturing of the car) does not produce greenhouse gases. There is no such an electric technology for large airplanes yet, nor is it likely to arrive in the coming decades. Current electric planes can carry up to 10 passengers for 
up to 1 hour of flight time; in 2035, electric planes are expected to be able to transport 50-100 passengers for $1,000 \mathrm{~km}$ - smaller in both capacity and distance than planes on kerosene.

The aviation industry tries to develop, produce and buy bio-kerosene, which is kerosene produced from plant-based sources. Bio-kerosene made from biomass grown in the Netherlands typically requires over 1,000 times more fresh water and arable land than the suggested alternative we present here. To put this into perspective, supplying Schiphol Airport in 2017 with bio-kerosene would require an amount of farmland 0.5-1.8 times the size of all Dutch farmland (depending on the crop, see 6). So far aviation has also used second generation biomass such as used cooking oil, which does not compete with food production, but cannot scale up as much as the alternatives. Investigation is ongoing for third generation biofuels (from algae), but this is currently not yet a viable option from a commercial or environmental perspective. In short, it seems like bio-kerosene cannot be the ultimate solution.

Hence, we need to look for another type of solution, maybe even unique to this sector. This 'synthetic' solution would be to replace the carbon atoms present in kerosene with reusable or renewable carbon atoms from a nonplant based source.

\section{There are various routes} to make synthetic kerosene.

Kerosene is a mixture of hydrocarbons, compounds consisting of many carbon $(\mathrm{C})$ and hydrogen $(\mathrm{H})$ atoms. To produce this energy-dense aviation fuel, we need a source of carbon atoms and a source of hydrogen atoms. It is possible to obtain carbon atoms by capturing carbon dioxide $\left(\mathrm{CO}_{2}\right)$ from the air via a process called direct air capture (DAC). Hydrogen atoms one can obtained by splitting water $\left(\mathrm{H}_{2} \mathrm{O}\right)$.

The technology to synthesise carbon and hydrogen atoms into kerosene exists $(4,5)$. And so an opportunity opens up to capture carbon and use the hydrogen atoms in water to make kerosene, using solar or wind electricity as energy source. The carbon and hydrogen go back into the atmosphere by burning it: when jet engines burn kerosene, carbon dioxide $\left(\mathrm{CO}_{2}\right)$ and water $\left(\mathrm{H}_{2} \mathrm{O}\right)$ are released. This would be a carbon neutral and circular economy solution (see figure 1).

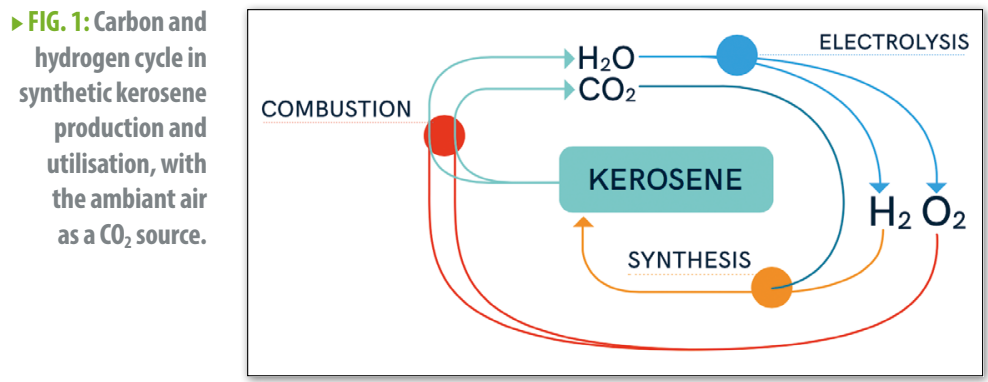

An intermediate step which would roughly halve emissions would be to take the carbon atoms initially from a concentrated source of $\mathrm{CO}_{2}$ emissions like an industrial plant and reuse the carbon. Then one would still use fossil carbon at the industrial plant from which $\mathrm{CO}_{2}$ is captured, and emit 'new' $\mathrm{CO}_{2}$ into the atmosphere when kerosene made from these fossil carbon atoms is burned. But because this fossil carbon is reused in synthetic kerosene, one would avoid the use of fossil kerosene and the emissions from the production of fossil kerosene - and therefore total emissions drop by $50 \%$.

We summarised the main principles of how one makes synthetic kerosene in figure 2 . Starting with carbon dioxide captured from the ambient air or an industrial plant, water and renewable electricity, a possible route would be to split the carbon dioxide into carbon monoxide + oxygen and the water into hydrogen + oxygen. There are various ways to do this. One way is to use an electrolyser that uses renewable electricity. Once one has carbon monoxide and hydrogen one has syngas and can use exactly the same process that Shell uses in its Pearl Plant in Qatar to make synthetic kerosene. The kerosene (mass) yield for this route is $61 \%$ (after recycling of light gases; the other product being diesel). The associated energy efficiency (excl. electricity generation) is 39\% if diesel is considered as a 'loss' and $63 \%$ if it is considered a product.

There are other routes as well, see box. The key idea is that it is possible to convert carbon dioxide, water and renewable electricity into synthetic kerosene. In the technical report (available on the web, 6) we explain the individual process steps that jointly form the renewable synthetic kerosene production chain. For each step we describe which organisations are active in this area, how the (chemical) process works, what the costs are now and what we may expect costs to be around 2030 (7). Lastly, we describe how we use this information in the business case model ( 6 and 7) we have developed to flexibly calculate the costs of most major synthetic kerosene production methods. This model as well as the technical report are freely available online.

\section{Carbon Neutral Kerosene in the Netherlands}

To get an idea of how much kerosene can be produced from the emissions of an industrial plant, we consider the following scenario. We take Tata Steel in Netherlands, as an example, as well as Schiphol Airport's kerosene consumption in 2016. Tata Steel emits enough carbon atoms to fuel approximately $50 \%$ of the airplanes that fuelled at Schiphol Airport in 2016. Alternatively, if we capture the carbon atoms directly from the ambient air, there is no carbon limit and we can fuel any airplane we want at Schiphol airport. We would however also need more DAC units, water and renewable electricity - which may have a large land and/or water footprint. 
To produce a large volume of hydrogen one also needs a large quantity of demineralised water. With the IJ-harbour nearby as well as the North Sea, water is not a limiting factor. One would need about $1 \%$ of the water demand of all Dutch households.

There are plans to build large offshore wind farms in the North Sea near the coast of IJmuiden, close to Tata Steel's production plant. Wind farms make electricity in variable quantities depending on how hard the wind blows. TenneT foresees that transporting that electricity (when wind farm electricity supply is high and Dutch electricity demand is low) to the rest of Europe will be quite expensive (9). Hence converting this peak supply near IJmuiden into hydrogen could be an alternative to extending the high voltage electricity grid, which may be cheaper as well.

The offshore wind electricity produced near IJmuiden around 2030 would be enough to make synthetic kerosene for approximately $1 / 3$ of the airplanes that fuelled at Schiphol airport in 2016. Of course, this renewable electricity is not only there for the production of synthetic kerosene, and society's electricity demand may surge if various sectors electrify simultaneously. However, renewable electricity is not only produced in windfarms near IJmuiden, but also in various other places on the North Sea as well as in onshore wind farms and solar panels.

Currently, the infrastructure to transport kerosene (pipeline to Schiphol Airport) and storage terminals are already in place in the Port of Amsterdam. Hence, if we produce synthetic kerosene in the Port of Amsterdam/ IJmuiden, we would not need significant additional infrastructure to secure supplies to Schiphol Airport. In fact, it would be an opportunity for regional embedding and integration of a novel cluster with a very wide reach.

\section{Pricing Carbon Neutral Kerosene}

Although we now know that we can produce semi (up to just over 50\% from waste gases of an industrial plant) or fully (up to $100 \%$ for direct air capture) carbon neutral kerosene, we do not know if we can also afford it. There are many uncertainties when exploring a pathway towards 2030. The main uncertainties turn out to be the costs of crude oil (main determinant of fossil kerosene costs) and of renewable electricity (main determinant of synthetic kerosene costs).

Although the price of solar and off-shore wind electricity has dropped considerably in the last few years, we do not know for sure how much further this cost reduction will go. Also we do not know what market prices will be if all sectors in society electrify simultaneously. The crude oil price is very volatile as well - it has been between 40 and 140 dollar per barrel in recent years.

A high price of fossil oil (for example 150 dollar per barrel, excluding taxes) makes fossil kerosene just as expensive as carbon neutral kerosene in our comparison in our base scenario. Similarly, a low price of renewable electricity (1.7 eurocents per kWh, excluding taxes) also puts carbon neutral kerosene at par with fossil kerosene. Of course, a combination of a slightly higher cost of oil and a slightly lower cost of electricity also creates cost parity. This could happen, for example, with oil at 120 dollar per barrel and electricity at 3 eurocents per kWh (7).

We see that, for example, the following set of assumptions delivers carbon neutral kerosene at the same costs as fossil kerosene in 2030.

- An oil price of 98 dollar per barrel (today's oil price is 80 dollar per barrel)

A fossil $\mathrm{CO}_{2}$ tax of 20 euro per tonne (today the $\mathrm{CO}_{2}$ ETS price is 26 euro per tonne)

\section{CURRENT INTERNATIONAL DEVELOPMENTS}

Recent developments have shown that large-scale synthetic kerosene production is perhaps even closer and cheaper than we thought.

Opus 12, in partnership with SoCalGas, showed that its technology can convert $\mathrm{CO}_{2}$ in a gas mixture (biogas) to methane in a single electrochemical step. It thus does not require a clean $\mathrm{CO}_{2}$ feed and can also produce other molecules (10). Climeworks, developer of DAC technology, built a new and more efficient DAC plant with integrated electrolysis and methanation unit, producing carbon neutral methane (11). The Opus 12 and Climeworks process could be integrated however, producing methane in a single step from water, renewable electricity and $\mathrm{CO}_{2}$ from the air.

Sunfire in Germany developed a high temperature co-electrolysis system, which produces syngas $(\mathrm{CO}$ and $\mathrm{H} 2)$ directly from $\mathrm{CO}_{2}$, water and renewable electricity (12). This implies significant savings in investment and operating costs for synthetic kerosene production compared to a system with individual $\mathrm{CO}$ and $\mathrm{H} 2$ production units. Carbon Engineering, developer of DAC technology, published an article in a peer-reviewed journal demonstrating that DAC is feasible at costs below $\$ 100 / \mathrm{tCO}_{2}$ (13). This provides a stronger basis to the claim that significant cost reductions in DAC technology can be achieved.

Lanzatech, which had already successfully produced synthetic jet fuel via ethanol from waste gases, saw the ASTM certify its use for commercial flight (14), supplied sustainable jet fuel to the world's first'steel gases' fuelled flight with Virgin Atlantic (15) and is on its way to develop a first commercial facility with a large consortium (16).

These developments combined paint a picture and envision production pathways that are closer, more cost-effective and more efficient than the ones we studied together in our research. It should therefore be exciting to see the first synthetic fuel production plants emerge. Lanzatech, Nordic Blue Crude and Carbon Engineering are amongst the first to announce the construction of synthetic fuel (pilot) production plants, while there are other consortia in the Netherlands, around the Port of Amsterdam and Rotterdam Airport, investigating this opportunity and probably others of whose existence we are not aware yet. 
- An electricity price of 2.9 eurocents per kWh (currently the average price of electricity is 4 eurocents per $k W h$, with solar and wind electricity sometimes pushing it towards 1 or 2 eurocents per $k W h$ )

- Oxygen, a by-product, is sold against production price

None of these assumptions seem very extreme. So the conclusion may be that it is possible to produce carbon neutral kerosene at (near) competitive costs in the near future.

Note that these costs are with the Netherlands as a reference point. Notably renewable electricity can be produced for lower costs in various other parts of the world. In fact, as the electricity price is the main determinant of synthetic kerosene costs, sourcing it for 2 eurocent $/ \mathrm{kWh}$ (8) rather than for 4 eurocent $/ \mathrm{kWh}$ could make synthetic kerosene cheaper than the fossil kerosene reference. However, transport cost to the Netherlands would then also have to be included, and the cost of capital may be higher (9).

Currently fuel makes up an estimated 15 - 40\% of a flight ticket's price (depending on various factors, including airline, flight distance and airports). In our base scenario for 2030 carbon neutral kerosene would add 20 $-50 \%$ to the price of the flight ticket compared to a 'fossil kerosene' ticket. However, if cost parity is reached, tickets would cost exactly the same, irrespective of fuel choice.

\section{Conclusions}

Our study shows that $\mathrm{CO}_{2}$ recycling for synthetic kerosene production for carbon neutral aviation could become a reality around 2030 . It is very likely that it can be done, and we can afford it if we assume modest changes to current prices. Furthermore, this seems the best option available for aviation to meet the goals of the Paris agreement by 2050 .

$\mathrm{CO}_{2}$ recycling for carbon neutral kerosene will however not stand on its own; instead it will be able to play a significant role in the energy system, not only by providing V FIG.2: renewable fuels for aviation, but also in its ability to balance Production process large variations in the supply and demand of electricity.

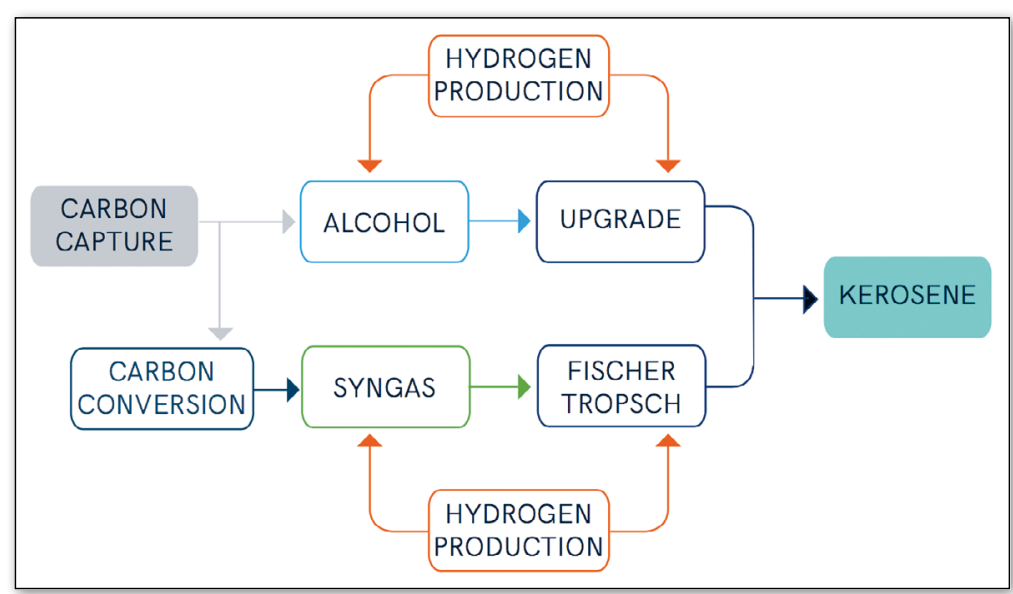

\section{About the Authors}

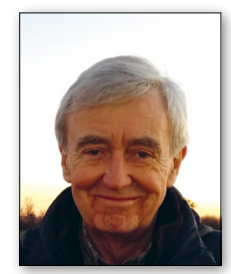

Frans W.Saris(franswsaris@gmail.com) is a physicist since 1964, first as (Silicon) researcher (at Amolf, AECL, Cornell, IBM, UNSW, ECN) later also as teacher (at Utrecht Cornell Leiden) and manager (at Amolf, ECN, Leiden, STW, Sanegeest) and science writer (NRC, Volkskrant, De Gids, TW, dNBg. www.franswsaris.nl - www.sanegeest.nl

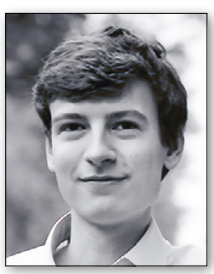

Rob Terwel is a partner at Kalavasta. He holds an MSc in Complex Systems (KCL) and $\mathrm{BSc}$ and BA in Liberal Arts and Sciences (UCU). He co-founded Kalavasta, Climate Neutral Strategies in 2017 and is responsible for research and modelling.

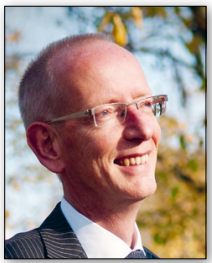

John Kerkhoven is a partner at Kalavasta. He holds a Phd in Marketing, Operations Research and Computer Science (WUR). He worked in the Chemical Industry for 10 years, was a partner a strategy firm Arthur D. Little Inc. and is since 2002 a serial entrepreneur focusing on the Energy Transition through companies like Quintel Strategy Consulting (now part of A.T. Kearney), Quintel Intelligence (www.energytransitionmodel.com ) and most recently Kalavasta, Climate Neutral Strategies.

\section{References}

[1] https://www.iata.org/publications/store/Pages/ 20-year-passenger-forecast.aspx

[2] https://www.icao.int/Meetings/aviationdataseminar/ Documents/ICAO-Long-Term-Traffic-Forecasts-July-2016.pdf

[3] https://www.icao.int/environmental-protection/CORSIA/ Pages/CORSIA-FAQs.aspx

[4] D. Marxer et al. (2015), Energy Fuels 29, 3241 (5)

[5] Adelbert Goede and Richard van der Sande, Europhysics News 47/3, 22 (2016)

[6] http://www.kalavasta.com/pages/projects/aviation.html and references in there

[7] https://pro.energytransitionmodel.com/

[8] Feasible according to a forthcoming Kalavasta report

[9] J. Ondraczek et al., Renewable Energy 75, 888 (2014)

[10] https://www.sempra.com/newsroom/press-releases/ socalgas-and-opus-12-successfully-demonstratetechnology-simplifies

[11] http://www.climeworks.com/climeworks-launches-dac-3plant-in-italy/

[12] https://www.sunfire.de/en/company/news/detail/ breakthrough-for-power-to-x-sunfire-puts-first-coelectrolysis-into-operation-and-starts-scaling

[13] https://carbonengineering.com/climate-change-breakthrough/

[14] http://www.lanzatech.com/jet-fuel-derived-ethanol-noweligible-commercial-flights/

[15] http://www.lanzatech.com/virgin-atlantic-lanzatechcelebrate-revolutionary-sustainable-fuel-project-takes-flight/

[16] http://www.lanzatech.com/lanzatech-virgin-atlantic-secureuk-government-grant-develop-world-first-waste-carbon-jetfuel-project-uk/ 